\title{
Mass Spectrometric Detection of Attomole Amounts of the Prion Protein by nanoLC/MS/MS
}

\author{
Bruce Onisko, ${ }^{\mathrm{a}}$ Irina Dynin, ${ }^{\mathrm{a}}$ Jesús R. Requena, ${ }^{\mathrm{b}}$ Christopher J. Silva, ${ }^{\mathrm{a}}$ \\ Melissa Erickson, ${ }^{\mathrm{a}}$ and John Mark Carter ${ }^{\mathrm{a}}$ \\ ${ }^{a}$ Western Regional Research Center, United States Department of Agriculture, Albany, California, USA \\ b Prion Research Unit, Department of Medicine, School of Medicine, University of Santiago, Santiago, Spain
}

\begin{abstract}
Sensitive quantitation of prions in biological samples is an extremely important and challenging analytical problem. Prions are the cause of several fatal neurodegenerative diseases known as transmissible spongiform encephalopathies (TSEs). At this time, there are no methods to diagnose TSEs in live animals or to assure a prion-free blood supply for humans. Prions have been shown to be present in blood by transfusion experiments, but based on the amount of infectivity found in these types of experiments, the amount of misfolded prion protein in blood is estimated to be only 30 to $625 \mathrm{amol} / \mathrm{mL}$. More sensitive detection of prions in brain would allow earlier detection of disease and assure a safer food supply. We studied quantitation of the prion protein by use of nanoscale liquid chromatography coupled to a tandem mass spectrometer using the multiple reaction monitoring mode of operation. We developed a method based on the detection of VVEQMCTTQYQK obtained by reduction, alkylation, and digestion with trypsin of the prion protein. Detection of VVEQMCTTQYQK was more sensitive than for the derivative with phenylisothiocyanate (PITC) because of decreased ionization efficiency of the PITC-derivatized peptides. The VVEQMCTTQYQK method has a LOD of 20 to $30 \mathrm{amol}$ for pure standards. Proof of principle is demonstrated by quantitation of the amount of PrP 27-30 in the brains of terminally ill Syrian hamsters. (J Am Soc Mass Spectrom 2007, 18, 1070-1079) (c) 2007 American Society for Mass Spectrometry
\end{abstract}

$\mathrm{P}$ rions are defined as infectious proteins [1], and have been shown to maintain epigenetic states in eukaryotes. In mammals, a prion $\left(\mathrm{PrP}^{\mathrm{Sc}}\right)$ is able to facilitate the conversion of the host's normal cellular protein $\left(\operatorname{PrP}^{\mathrm{C}}\right)$ into $\operatorname{PrP}^{\mathrm{Sc}}$ and thereby propagate an infection. $\mathrm{PrP}^{\mathrm{Sc}}$ is believed to be the cause of a group of fatal neurodegenerative diseases called transmissible spongiform encephalopathies (TSEs), known to affect humans and a variety of other animals [2-5]. Detailed studies show that the normal cellular isoform $\left(\mathrm{PrP}^{\mathrm{C}}\right)$ and the infectious isoform $\left(\mathrm{PrP}^{\mathrm{Sc}}\right)$ have identical amino acid sequences and covalent post-translational modifications and, thus, the difference between $\operatorname{PrP}^{\mathrm{C}}$ and $\mathrm{PrP}^{\mathrm{Sc}}$ is believed to be exclusively conformational [6-10].

$\operatorname{PrP}^{\mathrm{C}}$ and $\mathrm{PrP}^{\mathrm{Sc}}$ have distinct physico-chemical properties. For example, $\mathrm{PrP}^{\mathrm{C}}$ is rapidly degraded by proteinase $\mathrm{K}(\mathrm{PK})$, whereas $\mathrm{PrP}^{\mathrm{Sc}}$ is much more resistant to PK degradation. The most studied $\mathrm{PrP}^{\mathrm{Sc}}$ strain is the 263K strain propagated in hamsters. PK digestion of the 263K strain of $\mathrm{PrP}^{\mathrm{Sc}}$ cleaves the amino terminal domain to give an infectious core consisting primarily of 142 amino acids with an amino terminal Gly90 that is

Address reprint requests to Dr. Bruce Onisko, USDA/ARS/WRRC, 800 Buchanan St., Albany, CA 94710, USA. E-mail: bonisko@pw.usda.gov

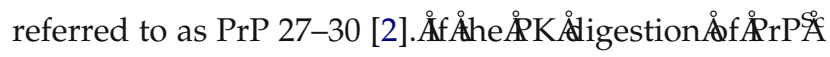
is done in the presence of detergents, rod-shaped particles are obtained, composed of monomers of $\operatorname{PrP}$ 27-30. By use of chemical cross-linking and mass spectrometry, the amino terminal Gly 90 residues of adjacent monomers in $\operatorname{PrP} 27-30$ rods have been shown to be located Åvithin $\AA 1$ Å fo fach

Sensitive prion detection is of importance, not only for research purposes, but also to solve a variety of problems such as the detection of preclinical TSE infections in humans and in animals (e.g., bovines, ovines, cervids), for the assurance of a safe blood supply, and for the early detection of prions in livestock. Prions are present in the blood of infected animals, since the disease has been shown to be transmitted by transfu-

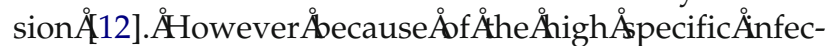
tivity of purified prion preparations (as high as $10^{11}$ infectious units (IU) per milligram of protein purified

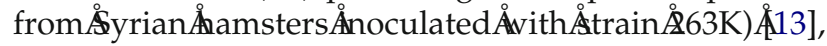
and the fact that in rodent models of TSE, blood contains 5 to $10 \mathrm{IU} / \mathrm{mL}$ in preclinical animals and a maximum of about $100 \mathrm{IU} / \mathrm{mL}$ at the time of disease onset, it has been estimated that blood contains about

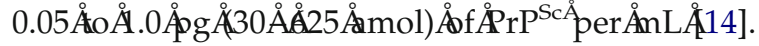

The incubation-time bioassay in hamster (or transgenic mice) is capable of detecting prions, but since 
biological assay requires 50 to 270 days, and needs a number of animals, it is not practical for routine testing

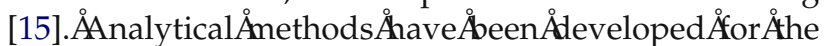
detection of $\operatorname{PrP}^{\mathrm{Sc}}$. They fall into three categories: Western blots, enzyme-linked immunosorbent assays (ELISAs), and the conformation dependent immunoassay (CDI). The most widely used test is the Western blot, which is reported to detect between 10 to 20 pmol

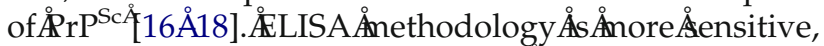

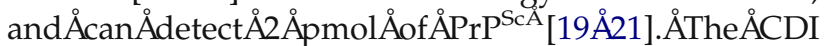
immunoassay is the most sensitive method reported, capable of detection of 0.1 pmol of $\mathrm{PrP}^{\mathrm{Sc}}$ in brain

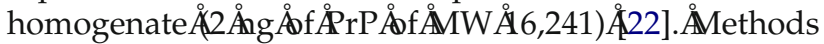
to amplify prion titer before detection using either cell culture [23] r considerable promise. Despite the advancements made in analytical methodology for prion analysis, apparently the detection limit needs to be improved by about three orders of magnitude to allow detection of prions in blood (vide supra, $30 \mathrm{amol} / \mathrm{mL}$ in blood versus 0.1 pmol detection by the best antibody methods).

Recently, tandem mass spectrometric methods using nanoscale chromatographic methods have demonstrated selective detection of proteins in biological ma-

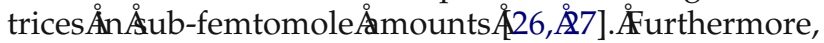
it has been suggested that the sensitivity of MS/MS detection of peptides may be improved through the use of phenylisothiocyanate (PITC) derivatives, since the MS/MS fragmentation of PITC derivatives gives considerably simplified spectra and thereby may enhance product ̊̊ion Âyields $\AA ̊[28, \AA 229]$. ÅWhereas Åtandem $A ̊ m a s s$ spectrometric methods have been used extensively in the structural characterization of the prion protein

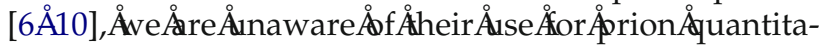
tion. We report the results of application of tandem mass spectrometric methods to the problem of detection of the prion protein, and to examine the effect of PITC derivatization on MS/MS sensitivity.

\section{Experimental}

\section{Chemicals}

Trypsin for in-gel digestion (porcine, sequencing grade, modified) was purchased from Princeton Separations, Adelphia, NJ. Bovine trypsin used for solution digestions was from Sigma (St. Louis, MO). Recombinant Syrian hamster PrP (rPrP) comprising amino acids 90-231 was obtained from InPro Biotechnology (South San Francisco, CA). The peptide VVEQMCTTQYQK, containing an iodoacetamide-derivatized cysteine, was synthesized by Anaspec (San Jose, CA). The structure of this synthetic peptide was confirmed by mass spectrometry; its purity was greater than $90 \%$ as shown by LC-UV, and the amount of peptide was quantitated by amino acid analysis. HPLC grade water was purchased from Burdick and Jackson (Muskegon, MI). Acetonitrile, HPLC grade, was from Fisher Scientific (Fairlawn,
NJ). All other reagents were from Sigma-Aldrich (St. Louis, MO).

\section{Reduction, Alkylation, and Tryptic Cleavage of Recombinant Syrian Hamster Prion Protein (90-231)}

Recombinant PrP containing residues 90-231 (6 nmol) was dissolved in $20 \mu \mathrm{L}$ of $8 \mathrm{M}$ guanidinium hydrochloride. The mixture was sonicated for $5 \mathrm{~min}$ and diluted with $20 \mu \mathrm{L}$ of $1 \mathrm{M}$ TRIS ( $\mathrm{pH}$ 8.0). To this solution was added $5 \mu \mathrm{L}(1 \mu \mathrm{mol})$ of a $200 \mathrm{mM}$ solution of DTT in $1 \mathrm{M}$ TRIS ( $\mathrm{pH}$ 8.0). The reaction mixture was kept at $35^{\circ} \mathrm{C}$ for 60 to $90 \mathrm{~min}$. After the reaction cooled to room temperature, $20 \mu \mathrm{L}(4 \mu \mathrm{mol})$ of a $200 \mathrm{mM}$ solution of iodoacetamide in 1M TRIS ( $\mathrm{pH} 8.0$ ) was added. The reaction was kept at room temperature in the dark for 60 to $90 \mathrm{~min}$. The excess iodoacetamide was quenched by addition of an additional $25 \mu \mathrm{L}$ of the DTT solution. The quenched solution was acidified with formic acid to $\mathrm{pH} 1.5$ to $2(25 \mu \mathrm{L})$. The reaction mixture containing the derivatized protein was purified by HPLC using an Alltech Altima C18 column $(150 \mathrm{~mm} \times 2.1 \mathrm{~mm}$ i.d., 5 $\mu \mathrm{m}$ particle diameter) using a flow rate of $0.25 \mathrm{~mL} / \mathrm{min}$ and a gradient of $20 / 80$ to $60 / 40$ (vol/vol) of A/B, where solvent $\mathrm{A}$ was $0.1 \%$ aqueous TFA and solvent $\mathrm{B}$ was acetonitrile/isopropanol/TFA ( 50/50/0.1). One major chromatographic peak was observed (monitoring the UV response at $210 \mathrm{~nm}$ ) and was collected. The identity and purity of the product was confirmed by LC/ESI/MS. Solvents were removed with a stream of nitrogen. The residue was dissolved in $400 \mu \mathrm{L}$ water and the $\mathrm{pH}$ adjusted to 8.5 by addition of $1 \mathrm{M} \mathrm{NH} \mathrm{NH}_{4} \mathrm{OH}$ $(15 \mu \mathrm{L})$. Bovine trypsin $(3.3 \mu \mathrm{g}$ in $33 \mu \mathrm{L}$ water) was added, and the reaction mixture was kept at $37^{\circ} \mathrm{C}$ overnight. The digestion was then stopped by addition of formic acid $(2 \mu \mathrm{L})$ to give a $\mathrm{pH}$ of 2.3 .

\section{Derivatization of the rPrP Tryptic Digest with PITC and Edman Cleavage}

To $0.5 \mathrm{nmol}$ of the tryptic digest was added $400 \mu \mathrm{L}$ of a freshly prepared $5 \%$ solution of phenylisothiocyanate (PITC) in ethanol/pyridine/water (1:1:1). The reaction mixture was kept at $45{ }^{\circ} \mathrm{C}$ for $35 \mathrm{~min}$, cooled to RT and then extracted three times with $1 \mathrm{~mL}$ portions of 2:1 heptane/ethyl acetate; organic extracts were discarded. A sample containing about 300 pmol of the PITCderivatized digest was taken to dryness with a stream of nitrogen. The residue was redissolved in $5 \mu \mathrm{L}$ of TFA, heated to $40{ }^{\circ} \mathrm{C}$ for $10 \mathrm{~min}$, then cooled to RT and diluted with $100 \mu \mathrm{L}$ of water.

\section{Qualitative Mass Spectrometry: Nanospray LC/MS/MS}

NanoLC/ESI/MS/MS was done with an Applied Biosystems (ABI/MDS SCIEX, Toronto, Canada) model 
QStar Pulsar equipped with a Proxeon Biosystems (Odense, Denmark) nanoelectrospray source. PrP digest samples $(20 \mu \mathrm{L}$ containing about $1 \mathrm{pmol})$ were loaded automatically onto a C-18 trap cartridge and chromatographed on a reversed-phase column (Vydac 238 EV5.07515, $75 \mu \times 150 \mathrm{~mm}$; Hesperia, CA) fitted at the effluent end with a coated spray tip (FS360-50-5-CE, New Objective Inc., Woburn, MA). A nanoflow LC system (Dionex, Sunnyvale, CA) with autosampler, column switching device, loading pump, and nanoflow solvent delivery system was used. Elution solvents were: A ( $0.5 \%$ acetic acid in water) and B ( $80 \%$ acetonitrile, $0.5 \%$ acetic acid). Samples were eluted at 250 $\mathrm{nL} / \mathrm{min}$ with the following binary gradient profile: $2 \%$ $\mathrm{B}$ at $0 \mathrm{~min}$ to $80 \% \mathrm{~B}$ in a 15 min linear gradient; held at $80 \%$ B for 5 min then back to $2 \%$ B for $10 \mathrm{~min}$. The QStar Pulsar was externally calibrated daily and operated above a resolution of 8000 . The acquisition cycle time of 6s consisted of a single $1 \mathrm{~s}$ MS "survey" scan followed by a $5 \mathrm{~s}$ MS/MS scan. Ions between $\mathrm{m} / \mathrm{z} 400$ to 1000 of charge states between +2 to +5 having intensities greater than 40 counts in the survey scan were selected for fragmentation. The dynamic exclusion window was set to always exclude previously fragmented masses. Collision energy optimized for charge state and $\mathrm{m} / \mathrm{z}$ was automatically selected by the Analyst QS software after adjusting parameters to obtain satisfactory fragmentation of human $\left[\mathrm{Glu}^{1}\right]$-fibrinopeptide $\mathrm{B}(+2)$, and human adrenocorticotropic hormone $(+3$ and +4$)$. Nitrogen was used for the collision gas and the pressure in the collision cell ranged from $3 \times 10^{-6}$ to $6 \times 10^{-6}$ torr.

\section{Quantitative Mass Spectrometry: Nanospray LC/MS/MS}

NanoLC/ESI/MS/MS was done with an Applied Biosystems (ABI/MDS SCIEX, Toronto, Canada) model 4000 Q-Trap instrument equipped with a nanoelectrospray source. Peptide samples ( $1 \mu \mathrm{L}$ containing $1 \mathrm{fmol}$ of human $\left[\mathrm{Val}^{5}\right]$-angiotensin II) were loaded automatically onto a C-18 trap cartridge and chromatographed on a reversed-phase column (Vydac 238EV5.07515, 75 $\mu$ x 150 mm; Hesperia, CA). A noncoated spray tip (FS360-2010-N-20-C12, New Objective Inc., Woburn, MA) was used with the Applied Biosystem source, model Microionspray. An LC Packings nanoflow LC system (Dionex, Sunnyvale, CA) with autosampler, column switching device, loading pump, and nanoflow solvent delivery system was used. Elution solvents and gradient profile were the same as described above.

The instrument response was optimized by loop injection of $20 \mu \mathrm{L}$ of a PrP digest at $1 \mathrm{pmol} / \mu \mathrm{L}$ of 50/49.5/0.5 (acetonitrile/water/acetic acid) onto a reversed-phase column (Vydac 238EV5.07515, 75 $\mu$ x 150 $\mathrm{mm}$; Hesperia, CA) using isocratic elution of 50/49.5/ 0.5 (acetonitrile/water/acetic acid) at 250 to $300 \mathrm{~nL} /$ $\mathrm{min}$. This method gave stable analyte signals for more than an hour per injection for tuning. Source parame- ters (electrospray voltage, curtain gas and nebulizing gas settings, ion source heater temperature, declustering potential, and nanospray tip positioning relative to the front plate orifice) were adjusted to obtain maximum analyte signal intensity in Q1MS scan mode while maintaining stable $( \pm 5 \%)$ electrospray intensity. Fragmentation to obtain specified product ions was optimized by adjusting the Q2 offset voltage ("collision energy").

\section{Syrian Hamster PrP 27-30}

A crude preparation of $\operatorname{PrP} 27-30$ was obtained from brains of terminally ill Syrian hamsters inoculated intracranially with the 263K strain of scrapie using modification fonethod

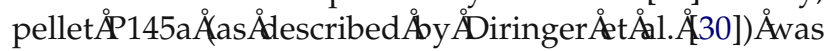
obtained, the next two detergent extraction steps were not performed, and pellet P145a was treated with benzonase and proteinase $\mathrm{K}$ as done with pellet P145c. The final pellet containing $\operatorname{PrP} 27-30$ was denatured by addition of $6 \mathrm{M}$ guanidinium hydrochloride, and protein was precipitated by centrifugation at $14,000 \mathrm{rpm}$ for 20 min with an Eppendorf model 5417R centrifuge (Hamburg, Germany) after addition of five volumes of methanol at $0{ }^{\circ} \mathrm{C}$.

\section{Electrophoretic Purification and In-Gel Proteolytic Digestion of PrP 27-30}

The PrP 27-30 pellet was dissolved with reducing Laemmli sample buffer, boiled for $10 \mathrm{~min}$ and subjected toÅSDS-PAGEÅ[31]Åusing Å\% \% ÅtoÅ12\%ÅNuPAGEÅgels (Invitrogen, Carlsbad, CA). The gel was stained with Coomassie blue, and the major protein bands were excised. In-gel digestion was done with a DigestPro (INTAVIS Bioanalytical Instruments AG, Bergisch Gladbach, Germany). Following washing, reduction with DTT, alkylation with iodoacetamide, and tryptic digestion, the peptides were eluted with 40 ul of $10 \%$ formic acid containing $0.1 \%$ trifluoroacetic acid.

\section{Results and Discussion}

Recombinant PrP (Syrian hamster, amino acid residues 90-231) was reduced with dithiothreitol, alkylated with iodoacetamide, purified by HPLC, then analyzed by nanoLC-ESI-TOF-MSÅsee Aigure $\AA$ ) Áo

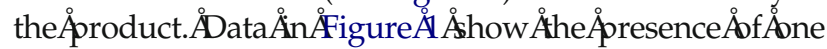
protein product present in charge states ranging from +13 to +22 . The $\mathrm{m} / \mathrm{z}$ data shown was transformed using the Bayesian Protein Reconstruct tool in the BioAnalyst ver. 1.1 software (Applied Biosystems, Foster City, CA), which resulted in a measured average molecular weight of 16,357 Da (theoretical average MW of 16,357.1 for $\mathrm{C}_{702} \mathrm{H}_{1073} \mathrm{~N}_{211} \mathrm{O}_{221} \mathrm{~S}_{11}$. The reduced and alkylated protein was then digested with trypsin. The tryptic digest, both before and after reaction with phenylisothiocyanate 


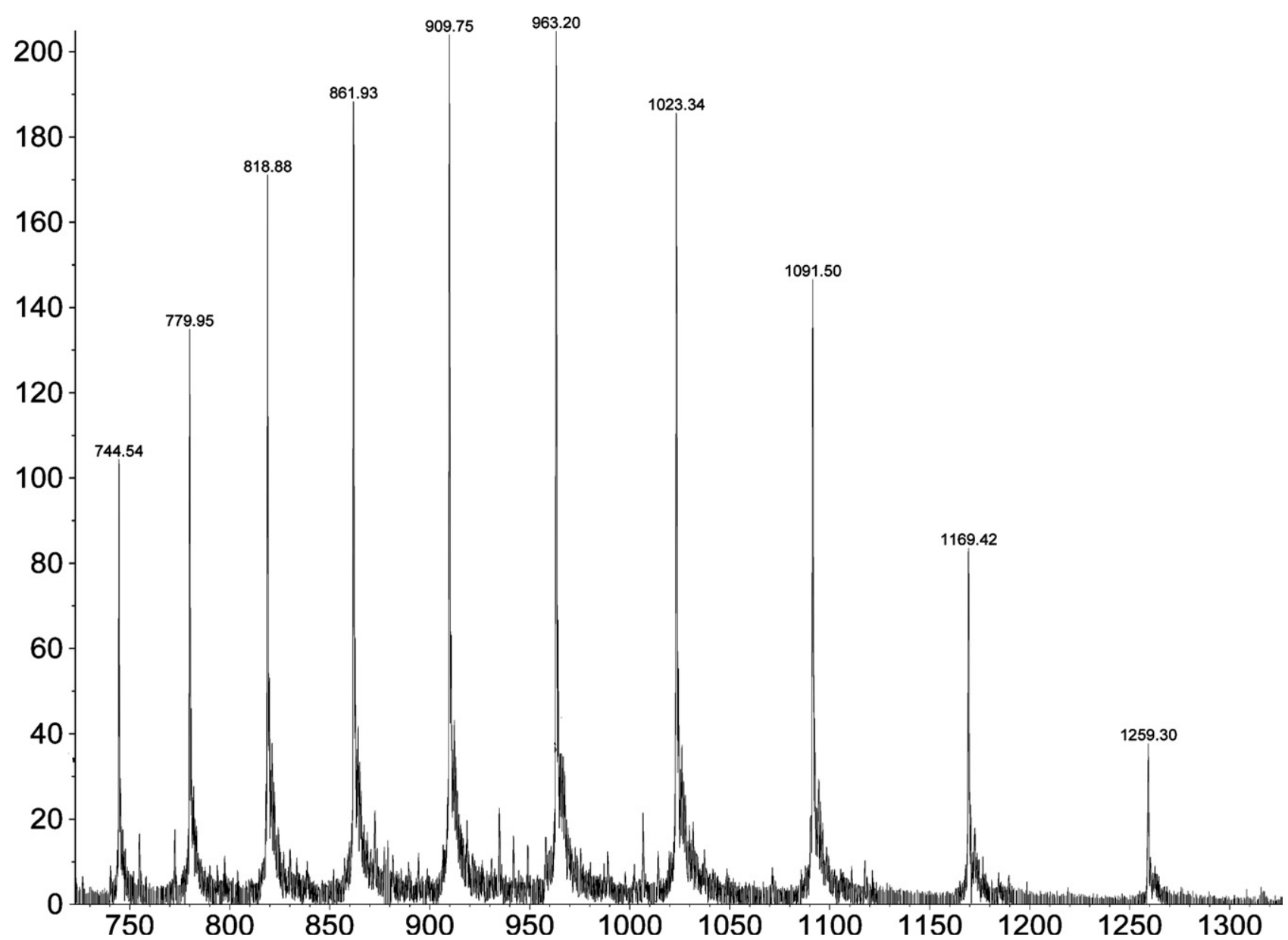

Figure 1. NanoLC/ESI/TOF/MS analysis of reduced and alkylated $\operatorname{rPrP}(90-231)$. The $\mathrm{x}$ axis is $m / z$.

(PITC), was analyzed by nanoLC/ESI/MS/MS on a quadrupole time-of-flight (Q-TOF) mass spectrometer. The four tryptic peptides that gave the most abundant signal, listed in decreasing abundance, were: GENFTETDIK, ESQAYYDGR, PMMHFGNDWEDR, and VVEQMCTTQYQK. After reaction with PITC, the four derivatized peptides that gave the most abundant signal, also listed in decreasing abundance, were GENFTETDIK, QHTVTTTTK, VVEQMCTTQYQK, and ESQAYYDGR. Proposed struc-

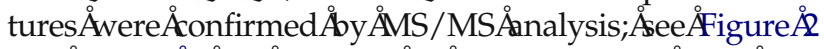

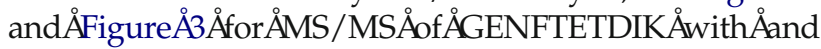
without PITC derivatization. Underivatized GENFTETDIK gave a complex (information-rich) spectrum showing excellent coverage of $y$ ions and good coverage of $b$ ions (see $\AA$ Figure $\AA 3$ ). APITC-derivatized $\AA$ GENFTETDIK ÅgaveÅa

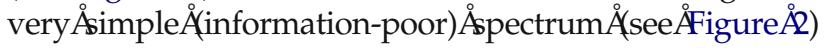
containing primarily the products of gas-phase Edman degradation $\left(b_{1}\right.$ and $\left.y_{n-1}\right)$, as observed by others with different $\AA$ PITC-derivatized $\AA$ peptides $\AA 28, \AA 9] . \AA$ AThe ically simplified MS/MS spectrum of the PITC derivative suggests that multiple reaction monitoring (MRM) analysis of the PITC derivative using either $b_{1}$ or $y_{n-1}$ as the selected product ion may give superior MRM response than the underivatized peptide.
Experiments were done to determine which fragment ion would give the best response for MRM analysis for GENFTETDIK, VVEQMCTTQYQK, and ESQAYYDGR before and after derivatization with PITC. For each peptide, digest samples were directly infused, ionized by nanoESI, and product ion scans were obtained at collision energies ranging from 10 to $110 \mathrm{~V}$. Three product ions were selected for each peptide: the most abundant immonium ion (or fragment thereof), the most abundant $b$ (or a) ion, and the most abundant y (or $x$ ion). Next, instrumental parameters for each transition were optimized. Relative responses for these 18 optimized transitions were obtained by nanoLC/MS/MS of injections of either the underivatized or the derivatized tryptic digest with the mass spectrometer operating in MRM mode. For all three Ånderivatized $\AA$ peptides $($ Table $\AA$ ), Åmonitoring $\AA$ the product ion of $\mathrm{m} / \mathrm{z} 84$, which corresponds to the immonium ion of lysine or glutamine (after loss of $\mathrm{NH}_{3}$ ), gave the best detector response. For all three PITC-derivatized $\AA$ peptides $\AA$ Table $\AA$ ), $\AA$ MRMÅsing $\AA{ }_{1}$ as the product ion gave the best response.

Direct comparison of the optimized nanoLC-MRM responses of the three tryptic peptides of interest with 


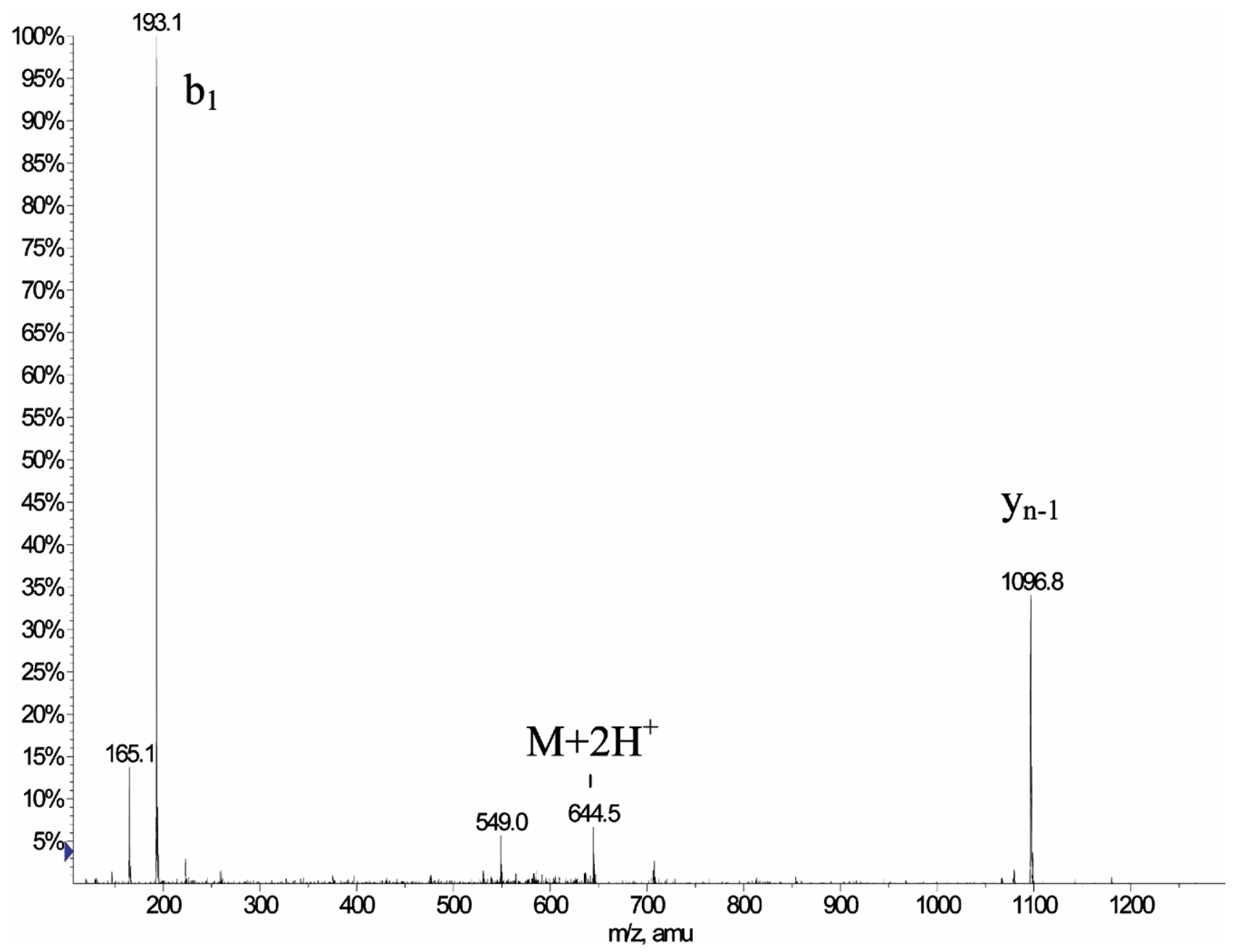

Figure 2. Collision Activated Decomposition (CAD) spectrum of PITC-GENFTETDIK obtained at a collision energy of $22 \mathrm{~V}$.

and without PITC derivatization was done with use of human $\left[\mathrm{Val}^{5}\right]$-angiotensin II $(1 \mathrm{fmol} /$ injection $)$ as an internal standard added to each digest. Samples were analyzed by nanoLC/MS/MS, and the MRM responses for the peptides were measured relative to the MRM response of the internal standard, and the MRM response of each underivatized peptide relative to the MRM response of the same peptide, after derivatization was calculated. PITC derivatization gave a diminished MRM response for all three peptides. The largest decrease, about 6-fold, was observed for GENFTETDIK. The MRM response for ESQAYYDGR was 2.5-fold greater than for PITC- ESQAYYDGR, and the MRM response for VVEQMCTTQYQK was 1.3-fold greater than for PITC- VVEQMCTTQYQK.

The decreased MRM responses seen for PITC-derivatized peptides could be the result of chemical instability of the PITC derivatives, decreased ionization efficiency, or decreased MRM efficiency. Potential chemical instability of the PITC derivatives was of concern, since our chromatographic solvents contained dilute acid, and PITC derivatives are known to degrade in acid. To test this possibility, the PITC-derivatized rPrP digest was acidified and heated to release the amino-terminal derivative. This sample was analyzed by nanoLC/ESI/TOF/MS, which confirmed that the desired cleavages had occurred. Furthermore, no PITCderivatized peptides remained, indicative of complete reaction. ENFTETDIK is the expected degradation product of PITC-GENFTETDIK. An MRM quantitation method for ENFTETDIK was developed on the Q-Trap model 4000 using a precursor ion of $m / z 547.7$, a product ion of $\mathrm{m} / \mathrm{z} 706.4$ and a collision energy of $28 \mathrm{~V}$. Using this method, and assuming a quantitative yield of ENFTETDIK from PITC-GENFTETDIK, the amount of ENFTETDIK in the PITC-derivatized $\mathrm{rPrP}$ digest was determined. For injections of 1.2, 30, and $150 \mathrm{fmol}$ of the PITC-derivatized $\mathrm{rPrP}$ digest, ENFTETDIK, as a percentage of the amount injected, was found to be $2.2 \%$, $2.6 \%$, and $2.5 \%$, respectively. Clearly, decomposition of the PITC-derivatized peptide, either before or during analysis, is not a significant problem.

MRM efficiency was estimated by calculating the percentage of the total ion current (TIC) present as the 


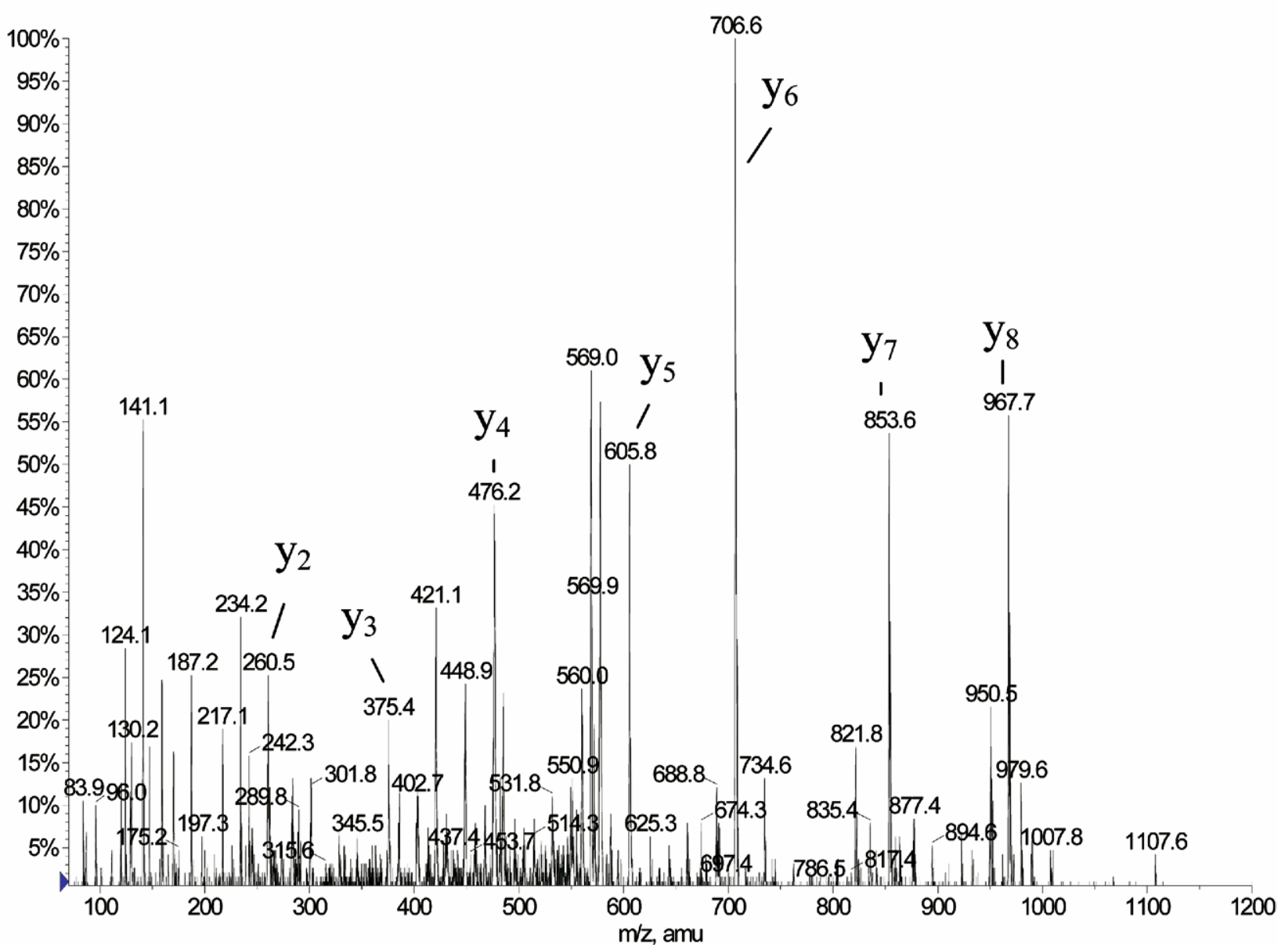

Figure 3. CAD spectrum of GENFTETDIK obtained at a collision energy of $30 \mathrm{~V}$.

product ion of interest using optimized instrumental parameters. For example, for PITC-GENFTETDIK (see Figure $\AA$ ), $\AA$ he $\AA_{1}$ product ion of $m / z 193$ monitored by MRM represents $33 \%$ of the TIC. For GENFTETDIK, the product ion of $\mathrm{m} / \mathrm{z} 84$ monitored by MRM under conditions optimized for detection of this fragment (see

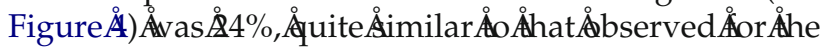
$b_{1}$ ion from the PITC derivative.

Thus, neither chemical instability of PITC derivatives nor diminished MRM efficiencies of the PITC-peptides can explain the observation that the nanoLC/ESI/MRM response of PITC-derivatized peptides was significantly less than that of the underivatized peptides. Presumably, the PITC derivatives have diminished ESI ionization efficiency. This has indeed been observed to be true forÅMALDIÅionization Åof ÅPITCÅderivatives Å[32]. ÅThis problem might be solved by using modified Edman reagents designed for enhanced ESI ionization efficiency of the product phenylthiohydantoins used in

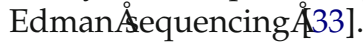

Table 1. Optimized MRM response for selected tryptic peptides from rPrP

\begin{tabular}{|c|c|c|c|c|c|c|c|c|c|c|}
\hline \multirow[b]{2}{*}{ Peptide } & \multirow[b]{2}{*}{$\begin{array}{c}z=2 \\
\text { precursor } \\
(\mathrm{m} / \mathrm{z})\end{array}$} & \multicolumn{3}{|c|}{$\begin{array}{l}\text { Optimized MRM for best } y \\
(\text { or } x) \text { ion }\end{array}$} & \multicolumn{3}{|c|}{$\begin{array}{l}\text { Optimized MRM for best b } \\
\text { (or a) ion }\end{array}$} & \multicolumn{3}{|c|}{$\begin{array}{l}\text { Optimized MRM for best } \\
\text { immonium ion }\end{array}$} \\
\hline & & $\begin{array}{l}\text { product } \\
\text { ion }(\mathrm{m} / \mathrm{z})\end{array}$ & $\begin{array}{l}\text { CE } \\
\text { (V) }\end{array}$ & $\begin{array}{l}\text { Relative } \\
\text { response }^{\text {a }}\end{array}$ & $\begin{array}{l}\text { Product } \\
\text { ion }(\mathrm{m} / \mathrm{z})\end{array}$ & $\begin{array}{l}\text { CE } \\
\text { (V) }\end{array}$ & $\begin{array}{l}\text { Relative } \\
\text { response }^{\text {a }}\end{array}$ & $\begin{array}{l}\text { product } \\
\text { ion }(\mathrm{m} / \mathrm{z})\end{array}$ & CE (V) & $\begin{array}{l}\text { Relative } \\
\text { response }^{a}\end{array}$ \\
\hline GENFTETDIK & 577.3 & $706.4(y 6)$ & 30 & $40+/-3$ & 1007.4(b9) & 20 & $2.6+/-0.3$ & $84.1^{b}$ & 100 & $100+/-5$ \\
\hline ESQAYYDGR & 544.7 & 673.3(y5) & 28 & $15+/-2$ & $579.2(\mathrm{~b} 5)$ & 22 & $1.0+/-0.2$ & $84.1^{b}$ & 100 & $18+/-3$ \\
\hline VVEOMCTTOYOK & 757.8 & $438.2(y 3)$ & 35 & $1.3+/-0.2$ & $171.1(\mathrm{a} 2)$ & 50 & $4.8+/-0.3$ & $84.1^{b}$ & 100 & $6.3+/-0.8$ \\
\hline
\end{tabular}

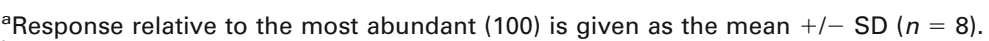

bThe ion of $m / z 84.1$ is the immonium ion of $\mathrm{K}$ (or $\mathrm{Q}$ ) after loss of $\mathrm{NH}_{3}$. 
Table 2. Optimized MRM response for selected tryptic peptides of $\mathrm{rPrP}$ derivatized with PITC

\begin{tabular}{|c|c|c|c|c|c|c|c|c|c|c|}
\hline \multirow[b]{2}{*}{ PITC-peptide } & \multirow{2}{*}{$\begin{array}{c}z=2 \\
\text { precursor } \\
(\mathrm{m} / \mathrm{z})\end{array}$} & \multicolumn{3}{|c|}{ Optimized MRM for $\mathrm{y}_{(\mathrm{n}-1)}$ ion } & \multicolumn{3}{|c|}{ Optimized MRM for $b_{1}$ ion } & \multicolumn{3}{|c|}{$\begin{array}{l}\text { Optimized MRM for best } \\
\text { immonium ion }\end{array}$} \\
\hline & & $\begin{array}{l}\text { Product ion } \\
(\mathrm{m} / \mathrm{z})\end{array}$ & $\begin{array}{l}\text { CE } \\
\text { (V) }\end{array}$ & $\begin{array}{l}\text { Relative } \\
\text { response }^{a}\end{array}$ & $\begin{array}{l}\text { Production } \\
(\mathrm{m} / \mathrm{z})\end{array}$ & $\begin{array}{l}\text { CE } \\
(\mathrm{V})\end{array}$ & $\begin{array}{l}\text { Relative } \\
\text { response }^{a}\end{array}$ & $\begin{array}{l}\text { Product } \\
\text { ion }(m / z)\end{array}$ & CE (V) & $\begin{array}{c}\text { Relative } \\
\text { response }^{a}\end{array}$ \\
\hline GENFTETDIK & 644.8 & 1096.5 (у9) & 22 & $79+/-8$ & $193.0(\mathrm{~b} 1)$ & 25 & $100+/-10$ & $120.1^{\mathrm{b}}$ & 85 & $16+/-2$ \\
\hline ESQAYYDGR & 612.2 & $959.4(y 8)$ & 20 & $32+/-4$ & 265.1 (b1) & 20 & $42+/-6$ & $102.1^{\mathrm{b}}$ & 56 & $15+/-2$ \\
\hline VVEOMCTTOYOK & 825.4 & $1415.6(y 11)$ & 32 & $16+/-2$ & 235.1 (b1) & 32 & $29+/-4$ & $101.1^{\mathrm{b}}$ & 90 & $2.2+/-0.3$ \\
\hline
\end{tabular}

${ }^{a}$ Responses are given as mean $+/-\mathrm{SD}(n=4)$.

blmmonium ions for the three peptides in descending order are from $F$, E, and $Q$, respectively. (Theoretical $m / z$ for $Q$ is 101.071 ; for $\mathrm{K}$ is 101.107 ; $m / z$ of 101.072 was observed on the Q-Star from MS/MS of VVEQMCTTQYOK).

Because of the superior MRM responses for the underivatized peptides, a PrP quantitation method was established without use of PITC. Of the three tryptic peptides that gave the best MRM sensitivity, VVEQMCTTQYQK was chosen for quantitation of the prion protein. GENFTETDIK was excluded because asparagine 197 is modified via N-linked oligosaccharides in the majority of naturally-occurring PrP molecules. ESQAYYDGR was also excluded since the peptide is absent in a carboxy-truncated species (about $10 \%$ to $15 \%$ A Aotal $\mathrm{RrP}$ ) Ås hserved VVEQMCTTQYQK by process of elimination. (PMMHFGNDWEDR is another good candidate, but the presence of two methionines makes possible four isomeric monosulfoxides (two positional and two diastereomeric) and two isomeric disulfoxides (diastereomeric). For VVEQMCTTQYQK, the a2 product ion of $\mathrm{m} / \mathrm{z} 171$ was chosen for MRM detection instead of the somewhat

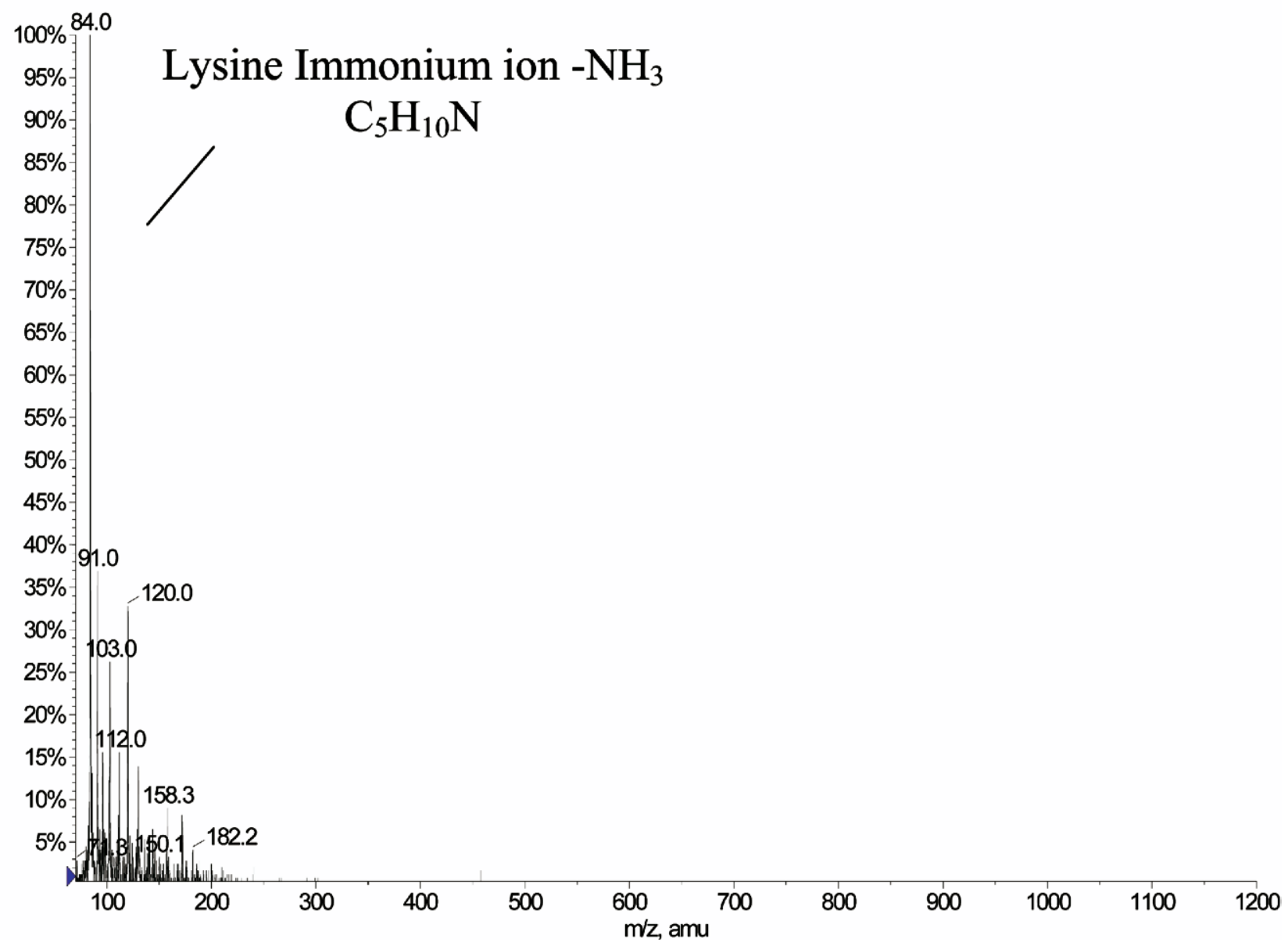

Figure 4. CAD spectrum of GENFTETDIK obtained at a collision energy of $100 \mathrm{~V}$. 


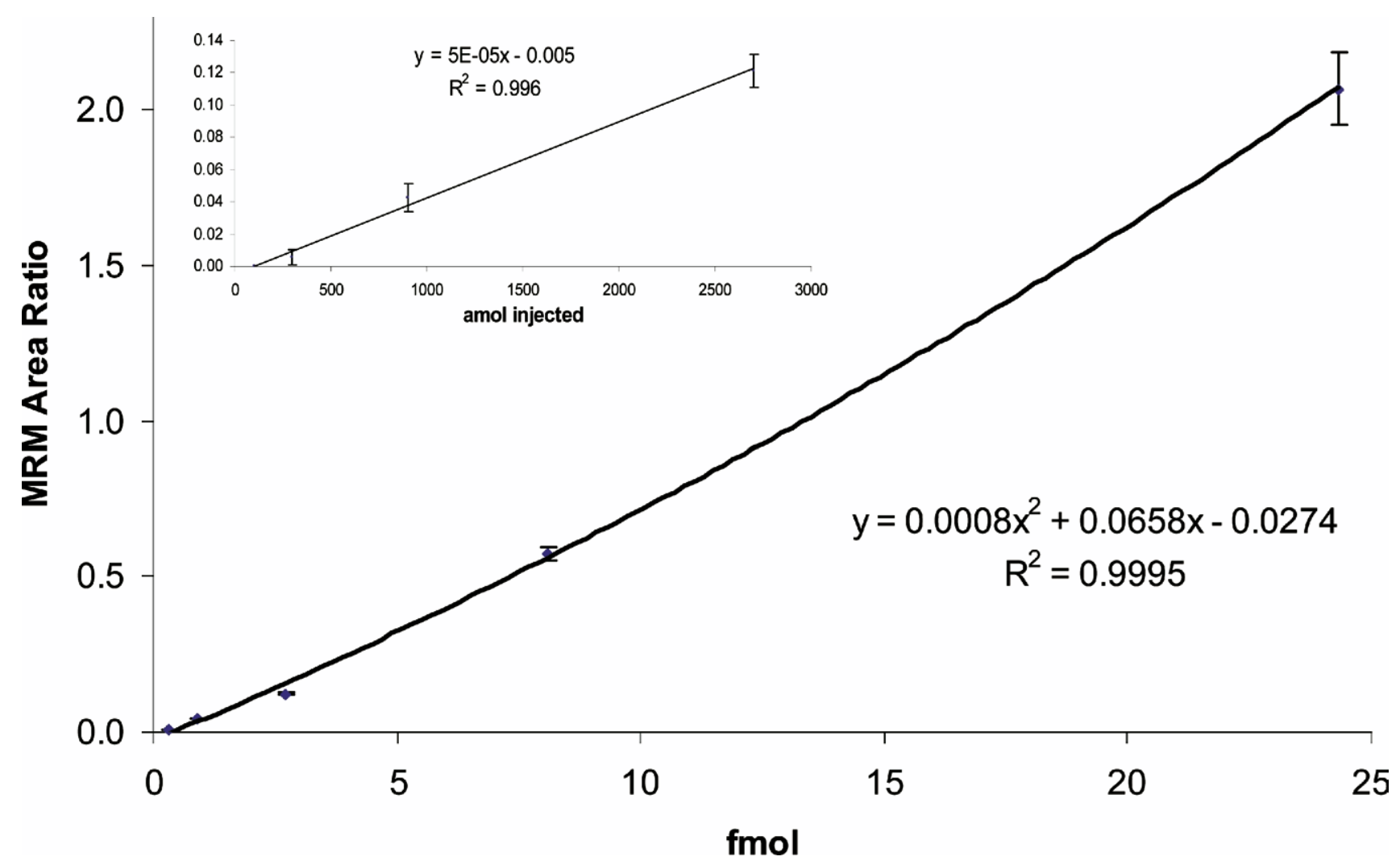

Figure 5. Area of MRM response of VVEQMCTTQYQK to the MRM response of the internal standard ( $1 \mathrm{fmol}$ human $\left[\mathrm{Val}^{5}\right]$-angiotensin II) versus amount of VVEQMCTTQYQK injected. Error bars show the mean \pm standard deviation $(n=5)$. The insert is an expansion of the results from the three lowest amounts injected. Data in the insert show the mean $\pm 3 *$ (standard deviations).

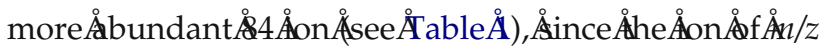
84 is expected from any peptide containing either lysine or glutamine, whereas the a2 ion should only be seen in MS/MS of peptides containing amino terminal VV, PK, or KP, only three of 400 possible dipeptides. A calibration curve using the optimized 757.8 to 171 transition

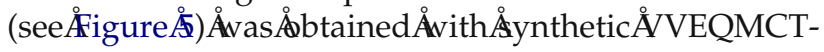
TQYQK, the amount of which had been quantitated by amino acid analysis, and using human $\left[\mathrm{Val}^{5}\right]$-angiotensin II ( $1 \mathrm{fmol} /$ injection) as internal standard. The results show a dynamic range of at least three orders of magnitude. Response is reasonably linear; however the data more closely fit a second-order polynomial, as shown. MRM responses for pentuplicate injections of

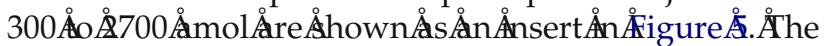
results for this range are linear $\left(\mathrm{r}^{2}\right.$ of 0.996$)$. Error bars in the insert are displayed as $+/-$ three times the calculated standard deviation for visual clarity. The chromatographic profile for 0 (solvent only), 300, and 900

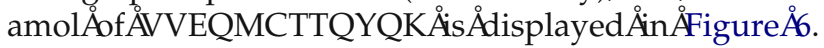
Signal to noise $(\mathrm{S} / \mathrm{N})$ was calculated using the standard deviation of the MRM response before elution of the analyte as an estimate of instrumental noise. For the pentuplicate injections of 900 amol of VVEQMCTTQYQK, a mean S/N of 126 was observed, from which a limit of detection (LOD) (defined as the amount that should give a $\mathrm{S} / \mathrm{N}=3$ ) of $20 \mathrm{amol}$ can be calculated. For the pentuplicate injections of $300 \mathrm{amol}$ of VVEQMCTTQYQK, a mean $\mathrm{S} / \mathrm{N}$ of 33 was observed, from which a LOD of 30 amol can be calculated for detection of the prion protein. The LOD of 20 to 30 amol achieved by nanoLC/MRM is nearly four orders of magnitude more sensitive than the $0.2 \mathrm{pmol}$ sensitivity reported for the most sensitive antibody-based detection method (vide supra) 222$]$.

A crude preparation of PrP 27-30 was obtained from the brains of terminally ill Syrian hamsters inoculated intracranially with the $263 \mathrm{~K}$ strain of scrapie. The sample preparation comprised tissue homogenization, centrifugation to obtain a sarkosyl-insoluble pellet, treatment with benzonase and proteinase $K$, then further purification by SDS-PAGE. Three bands are seen for PrP 27-30 by SDS-PAGE and are known to correspond to molecular species containing 0,1 , or $2 \mathrm{~N}$ linked glycans per molecule. Our SDS-PAGE separation clearly resolved the band containing no N-linked glycans from the other two bands that were poorly resolved (data not shown). Subsequently, we excised only two gel regions: one containing PrP with no N-linked glycans and the other containing PrP with either one or two N-linked glycans. Excised gel regions were destained, reduced, alkylated, treated with trypsin, the resulting peptides were extracted, and the amount of 

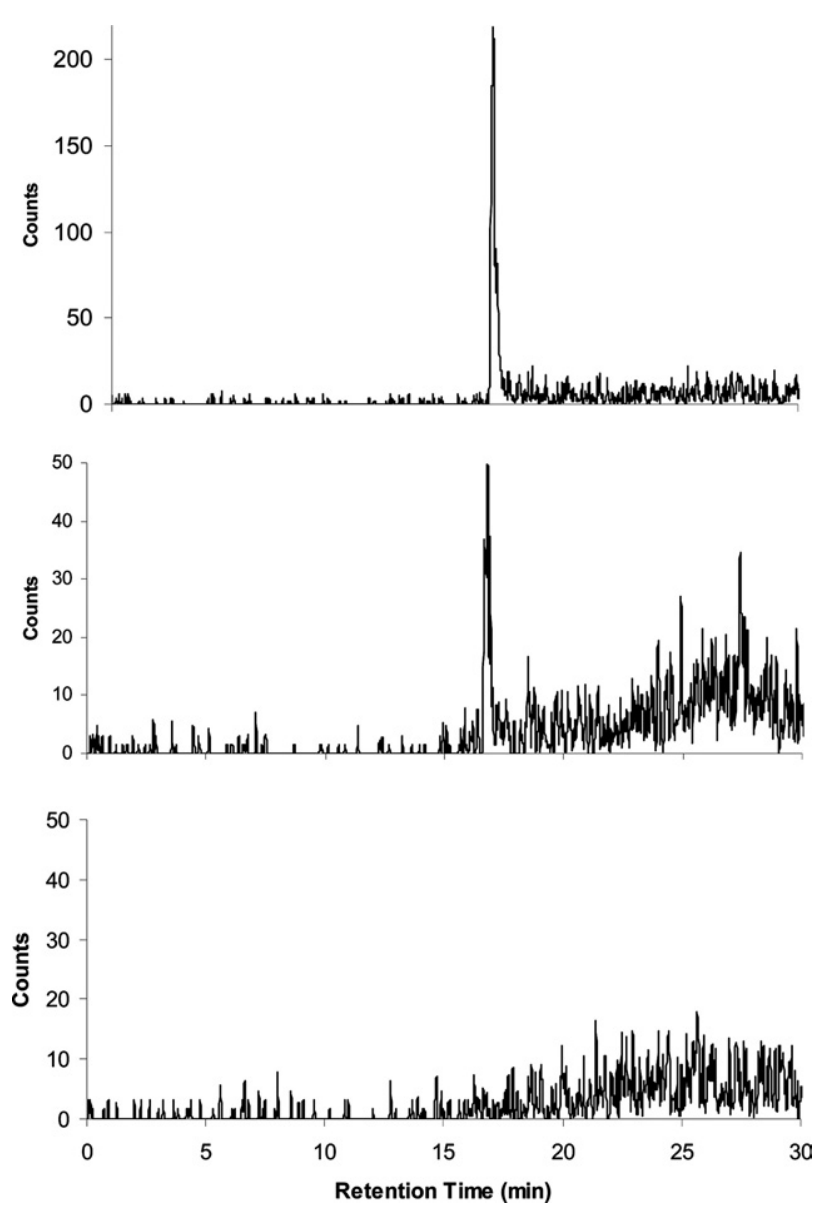

Figure 6. Elution profile (MRM response) for injection of 0,300 , and 900 amol of VVEQMCTTQYQK. Data has been smoothed, but $\mathrm{S} / \mathrm{N}$ and LOD in the text were calculated using raw data.

VVEQMCTTQYQK was quantitated using the method described (vide supra).

Recovery experiments were performed to estimate the overall yield of the chemical, enzymatic, and physical steps used after isolation of crude $\operatorname{PrP} 27-30$. Various amounts of $\operatorname{rPrP}$ (quantitated by OD at $254 \mathrm{~nm}$ ) were subjected to SDS-PAGE, in-gel digestion, and quantitation of VVEQMCTTQYQK by nanoLC/ESI/ MRM as done for PrP 27-30. The results, shown in

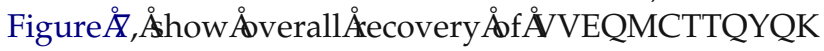
from $\mathrm{rPrP}$ ranging from $9 \%$ to $33 \%$, depending on the amount of starting $\mathrm{rPrP}$.

The amounts of VVEQMCTTQYQK obtained from the excised gel pieces from SDS-PAGE of crude PrP 27-30 were corrected using the estimated recoveries

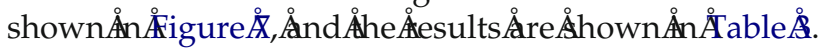
We estimate $19 \mathrm{ug} / \mathrm{g}$ of brain (wet weight) of PrP 27-30 in terminally ill hamsters, composed of $1.2 \mathrm{ug} / \mathrm{g}$ of PrP 27-30 containing no N-linked glycans and $17 \mathrm{ug} / \mathrm{g}$ of PrP 27-30 containing N-linked glycans. This result is in excellent agreement with the estimate by Diringer et al. [30]

Using pure standards, it is straight forward to compare the LOD for our method ( $30 \mathrm{amol})$ to that of the

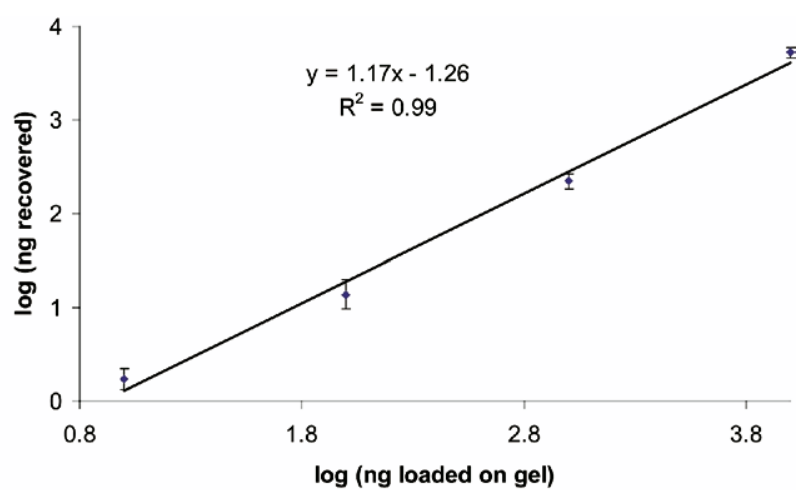

Figure 7. Recovery of VVEQMCTTQYQK after SDS-PAGE purification, reduction, alkylation, and tryptic cleavage of recombinant Syrian hamster PrP comprising amino acids 90-231.

CDI (300 amol, calculated from $5 \mathrm{pg}$ protein of MW 16,240)Å[22]; $\AA$ the Åmass $\AA$ spectrometric Amethod Åappears about ten times more sensitive. Detection of prions in biological materials is much more difficult, and a comparison of the LOD of our method with the CDI starting with brain can be estimated. To obtain the results for

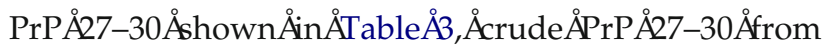
$0.57 \mathrm{~g}$ brain (wet weight) was loaded on each SDSPAGE lane, the major band was excised and processed as described by in-gel digestion to give $150 \mathrm{uL}$ of digest. After a 10-fold dilution of this digest, $1 \mathrm{uL}$ was injected onto the nanoLC column, and the MRM response (raw data not shown) gave a single peak of the correct retention time with an average $\mathrm{S} / \mathrm{N}$ for triplicate injections of 2250. This corresponds to a calculated LOD of 110 amol for PrP 27-30 from brain, about three times higher than the LOD found with pure standard peptide, presumably because of the $33 \%$ recovery obtained with this Åmount in brain samples, our \% recovery should be about three

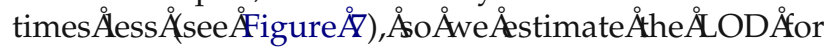
detection of ng amounts of $\operatorname{PrP} 27-30$ from brain to be about 300 amol, which is about 300 times more sensitive than the reported LOD of $0.1 \mathrm{pmol}$ for the CDI using rPrP in brain homogenate (2 ng of PrP of MW 16,240) [22].

In conclusion, we have developed a mass spectrometric method for quantitation of the prion protein and demonstrated its use in detection of PrP 27-30 in the brains of terminally ill Syrian hamsters. This method is appropriate for detection of $\mathrm{PrP}^{\mathrm{Sc}}$, and has better sensitivity than any published antibody-based method.

Table 3. Quantitation of PrP 27-30 molecular species in brains of terminally ill Syrian hamsters

\begin{tabular}{lc}
\hline \multicolumn{1}{c}{ Molecular species } & ${\text { Amount ug/g brain })^{\mathrm{a}}}^{\mathrm{c}}$ \\
\hline \hline PrP 27-30 with no N-linked glycans & $1.2+/-0.2(3)$ \\
PrP 27-30 with either 1 or 2 N- & $17+/-2(3)$ \\
$\quad$ linked glycans & $19+/-2(3)$ \\
\hline
\end{tabular}

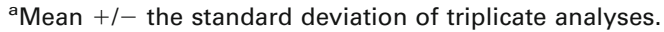


Future studies will focus on sample preparation for attempts to detect $\mathrm{PrP}^{\mathrm{Sc}}$ in blood.

\section{Acknowledgments}

The authors acknowledge Dr. William Vensel and Dr. Christine Hunter for discussions that were significant to the completion of this work.

\section{References}

1. Prusiner, S. B. Novel Proteinaceous Infectious Particles Cause Scrapie. Science 1982, 216(4542), 136-144.

2. Prusiner, S. B. Prions. Proc. Natl. Acad. Sci. U.SA. 1998, 95(23), 13363 13383.

3. Soto, C. Diagnosing Prion Diseases: Needs, Challenges and Hopes. Nat. Rev. Microbiol. 2004, 2(10), 809-819.

4. Aguzzi, A.; M. Polymenidou. Mammalian Prion Biology: One Century of Evolving Concepts. Cell 2004, 116(2), 313-327.

5. Prusiner, S. B. Molecular Biology of Prion Diseases. Science 1991, 252(5012), 1515-1522.

6. Stahl, N.; Baldwin, M. A.; Teplow, D. B.; Hood, L.; Gibson, B. W.; Burlingame, A. L.; Prusiner, S. B. Structural Studies of the Scrapie Prion Protein Using Mass Spectrometry and Amino Acid Sequencing. Biochemistry 1993, 32(8), 1991-2002.

7. Stahl, N.; Baldwin, M. A.; Hecker, R.; Pan, K. M.; Burlingame, A. L.; Prusiner, S. B. Glycosylinositol Phospholipid Anchors of the Scrapie and Cellular Prion Proteins Contain Sialic Acid. Biochemistry 1992, 31(21), 5043-5053.

8. Stahl, N.; Baldwin, M. A.; Prusiner, S. B. Electrospray Mass Spectrometry of the Glycosylinositol Phospholipid of the Scrapie Prion Protein. Cell. Biol. Int. Rep. 1991, 15(9), 853-862.

9. Baldwin, M. A.; Stahl, N.; Reinders, L. G.; Gibson, B. W.; Prusiner, S. B.; Burlingame, A. L. Permethylation and Tandem Mass Spectrometry of Oligosaccharides Having Free Hexosamine: Analysis of the Glycoinositol Phospholipid Anchor Glycan from the Scrapie Prion Protein. Anal. Biochem. 1990, 191(1), 174-182.

10. Stahl, N.; Baldwin, M. A.; Burlingame, A. L.; Prusiner, S. B. Identification of Glycoinositol Phospholipid Linked and Truncated Forms of the Scrapie Prion Protein. Biochemistry 1990, 29(38), 8879-8884.

11. Onisko, B.; Fernandez, E. G.; Freire, M. L.; Schwarz, A.; Baier, M. Camina, F.; Garcia, J. R.; Rodriguez-Segade Villamarin, S.; Requena, J. R. Probing PrPSc Structure Using Chemical Cross-Linking and Mass Spectrometry: Evidence of the Proximity of Gly90 Amino Termini in the PrP 27-30 Aggregate. Biochemistry 2005, 44(30), 10100-10109.

12. Hunter, N.; Foster, J.; Chong, A.; McCutcheon, S.; Parnham, D.; Eaton, S.; MacKenzie, C.; Houston, F. Transmission of Prion Diseases by Blood Transfusion. J. Gen. Virol. 2002, 83(Pt 11), 2897-2905.

13. Prusiner, S. B.; McKinley, M. P.; Bowman, K. A.; Bolton, D. C.; Bendheim, P. E.; Groth, D. F.; Glenner, G. G. Scrapie Prions Aggregate to Form Amyloid-Like Birefringent rods. Cell 1983, 35(2 Pt 1), 349-358.

14. Brown, P. L.; Cervenakova, L.; Diringer, H. Blood Infectivity and the Prospects for a Diagnostic Screening Test in Creutzfeldt-Jakob Disease. J. Lab. Clin. Med. 2001, 137(1), 5-13.

15. Prusiner, S. B.; Cochran, S. P.; Groth, D. F.; Downey, D. E.; Bowman, K. A.; Martinez, H. M. Measurement of the Scrapie Agent Using an Incubation Time Interval Assay. Ann. Neurol. 1982, 11(4), 353-358.

16. Wadsworth, J. D.; Joiner, S.; Hill, A. F.; Campbell, T. A.; Desbruslais, M.; Luthert, P. J.; Collinge, J. Tissue Distribution of Protease Resistant Prion
Protein in Variant Creutzfeldt-Jakob Disease Using a Highly Sensitive Immunoblotting Assay. Lancet 2001, 358(9277), 171-180.

17. Zanusso, G.; Righetti, P. G.; Ferrari, S.; Terrin, L.; Farinazzo, A. Cardone, F.; Pocchiari, M.; Rizzuto, N.; Monaco, S. Two-Dimensional Mapping of Three Phenotype-Associated Isoforms of the Prion Protein in Sporadic Creutzfeldt-Jakob Disease. Electrophoresis 2002, 23(2), 347355.

18. Lee, D. C.; Stenland, C. J.; Hartwell, R. C.; Ford, E. K.; Cai, K.; Miller, J. L.; Gilligan, K. J.; Rubenstein, R.; Fournel, M.; Petteway, S. R., Jr. Monitoring Plasma Processing Steps With a Sensitive Western Blot Assay for the Detection of the Prion Protein. J. Virol. Methods 2000, 84(1), 77-89.

19. Deslys, J. P.; Comoy, E.; Hawkins, S.; Simon, S.; Schimmel, H.; Wells, G.; Grassi, J.; Moynagh, J. Screening Slaughtered Cattle for BSE. Nature 2001, 409(6819), 476-478.

20. Biffiger, K.; Zwald, D.; Kaufmann, L.; Briner, A.; Nayki, I.; Purro, M.; Bottcher, S.; Struckmeyer, T.; Schaller, O.; Meyer, R.; Fatzer, R.; Zurbriggen, A.; Stack, M.; Moser, M.; Oesch, B.; Kubler, E. Validation of a Luminescence Immunoassay for the Detection of $\operatorname{PrP}\left(\mathrm{Sc}_{\mathrm{c}}\right)$ in Brain Homogenate. J. Virol. Methods 2002, 101(1/2), 79-84.

21. Grassi, J.; Comoy, E.; Simon, S.; Creminon, C.; Frobert, Y.; Trapmann, S.; Schimmel, H.; Hawkins, S. A.; Moynagh, J.; Deslys, J. P.; Wells, G. A Rapid Test for the Preclinical Post Mortem Diagnosis of BSE in Central Nervous System Tissue. Vet. Rec. 2001, 149(19), 577-582.

22. Safar, J.; Wille, H.; Itri, V.; Groth, D.; Serban, H.; Torchia, M.; Cohen, F. E.; Prusiner, S. B. Eight Prion Strains Have $\operatorname{PrP}\left(\mathrm{Sc}_{\mathrm{c}}\right)$ Molecules with Different Conformations. Nat. Med. 1998, 4(10), 1157-1165.

23. Klohn, P. C.; Stoltze, L.; Flechsig, E.; Enari, M.; Weissmann, C. A Quantitative, Highly Sensitive Cell-Based Infectivity Assay for Mouse Scrapie Prions. Proc. Natl. Acad. Sci. U.S.A. 2003, 100(20), 11666-11671.

24. Castilla, I.; Saa, P; Soto, C. Detection of Prions in Blood. Nat. Med. 2005, 11(9), 982-985.

25. Supattapone, S. Prion Protein Conversion in Vitro. J. Mol. Med. 2004, 82(6), 348-356.

26. Lu, Y.; Bottari, P.; Turecek, F.; Aebersold, R.; Gelb, M. H. Absolute Quantification of Specific Proteins in Complex Mixtures Using Visible Isotope-Coded Affinity Tags. Anal. Chem. 2004, 76(14), 4104-4111.

27. Gerber, S. A.; Rush, J.; Stemman, O.; Kirschner, M. W.; Gygi, S. P. Absolute Quantification of Proteins and Phosphoproteins from Cell Lysates by Tandem MS. Proc. Natl. Acad. Sci. U.S.A. 2003, 100(12), 6940-6945

28. Sidhu, K. S. Sangvanich, P. Brancia, F. L.; Sullivan, A. G.; Gaskell, S. J Wolkenhaue, O.; Oliver, S. G.; Hubbard, S. J. Bioinformatic Assessment of Mass Spectrometric Chemical Derivatization Techniques for Proteome Database Searching. Proteomics 2001, 1(11), 1368-1377.

29. van der Rest, G.; He, F.; Emmett, M. R.; Marshall, A. G.; Gaskell, S. J. Gas-Phase Cleavage of PTC-Derivatized Electrosprayed Tryptic Peptides in an FT-ICR Trapped-Ion Cell: Mass-Based Protein Identification Without Liquid Chromatographic Separation. J. Am. Soc. Mass Spectrom. 2001, 12(3), 288-295.

30. Diringer, H.; Beekes, M.; Ozel, M.; Simon, D.; Queck, I.; Cardone, F. Pocchiari, M.; Ironside, J. W. Highly Infectious Purified Preparations of Disease-Specific Amyloid of Transmissible Spongiform Encephalopathies Are Not Devoid of Nucleic Acids of Viral Size. Intervirology 1997, $40(4), 238-246$

31. Laemmli, U. K. Cleavage of Structural Proteins During the Assembly of the Head of Bacteriophage T4. Nature 1970, 227(5259), 680-685.

32. Tholey, A.; Wittmann, C.; Kang, M. J.; Bungert, D.; Hollemeyer, K.; Heinzle, E. Derivatization of Small Biomolecules for Optimized MatrixAssisted Laser Desorption/Ionization Mass Spectrometry. J. Mass Spectrom. 2002, 37(9), 963-973.

33. Ducret, A.; Bures, E. J.; Aebersold, R. High-Sensitivity Detection of 4-(3-Pyridinylmethylaminocarboxypropyl) Phenylthiohydantoins by Capillary Liquid Chromatography-Microelectrospray Ion Trap Mass Spectrometry. J. Protein Chem. 1997, 16(5), 323-328. 